\title{
Cardiovascular outcome trials in type 2 diabetes: what have we learned from the past and present?
}

\author{
Gautam Das
}

Correspondence: gautam.das@wales.nhs.uk

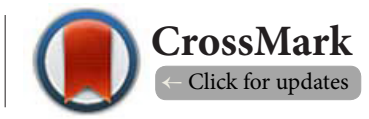

Department of Diabetes and Endocrinology, Prince Charles Hospital, Cwm Taf University Health Board, Merthyr Tydfil, CF47 9DT, United Kingdom.

\begin{abstract}
There is a wealth of epidemiological data which shows that type 2 diabetes significantly increase the risk of cardiovascular events. The evidence from earlier trials have demonstrated that improvement in glycated haemoglobin will reduce the risk of micro vascular disease but there is lack of robust evidence to suggest whether improvement in glycaemic control will have similar beneficial outcomes on macro vascular disease. In the last few years there have been a paradigm shift by which cardiovascular trials relating to therapy in type 2 diabetes are being conducted as every new drug needs to demonstrate cardiovascular safety as per the requirements set by several health regulatory authorities. This has led to alteration in study designs, duration for which they are conducted and end points which are being assessed. As a result, the intended risks and benefits relating to these newer agents are insufficiently explored which may have potential implications in long term management of a chronic disease like type 2 diabetes. This article provides a comparison between past and present cardiovascular outcome trials focussing mainly on oral agents used in type 2 diabetes and also explores the challenges encountered in conducting such trials.
\end{abstract}

Keywords: Type 2 diabetes, glycated haemoglobin, cardiovascular, trials

\section{Introduction}

The risk of cardiovascular disease (CVD) is twice in people with type 2 diabetes when compared to people without diabetes after adjustment for established cardiovascular (CV) risk factors [1]. Prospective epidemiological and experimental studies have reported an association between suboptimal glycaemic control [measured by an elevated glycated haemoglobin ( $\mathrm{HbA1c})]$ and both micro and macro vascular complications $[2,3]$. It was found that the relative risk for coronary heart disease (CHD) or stroke has been estimated at $1.18 \%(95 \% \mathrm{Cl}: 1.10-1.26)$ for every $1 \%$ increase in $\mathrm{HbA} 1 \mathrm{c}$ [4]. In recognition of the graded relationship between glycaemic control and $\mathrm{CV}$ events a major shift has taken place in the recent years to develop evidence based treatment strategies for type 2 diabetes that will not only reduce the disease progression but will also reduce the CV disease burden and will prolong life.

Nissen and Wolski published a meta-analysis in 2007 suggesting that rosiglitazone was associated with significant risk of myocardial infarction (MI) and with increase risk of death from CV causes [5]. Their finding initiated an intense debate about the CV safety of the antidiabetic drugs and led to a remarkable change in the landscape of subsequent diabetic trials that have been conducted over the last few years. The US FDA revised their approval process for newer antidiabetic agents recommending that apart from lowering $\mathrm{HbA} 1 \mathrm{c}$ which remains an acceptable primary efficacy endpoint sponsors should demonstrate that the therapy does not increase $\mathrm{CV}$ risk to an unacceptable extent [6]. The guidance also suggested that if the premarketing application contains clinical data that showed that the upper bound of the two-sided $95 \%$ confidence interval $(\mathrm{Cl})$ for the estimated increased risk (i.e., risk ratio) is between 1.3 and 1.8, and the overall risk benefit analysis supports approval, a post marketing trial will be needed to definitely show that upper bound of the two-sided $95 \% \mathrm{Cl}$ for the estimated risk ratio is less than 1.3. This essentially meant that the trials needed to be adequately powered and should include patients who are at higher risk of CV events, such as patients with relatively advanced disease, elderly and patients with some degree of renal impairment [6]. This has led to a plethora of $\mathrm{CV}$ outcome trials with glucose lowering agents in 
type 2 diabetes which are mostly and typically event-driven and are conducted to satisfy regulatory requirements in the shortest possible time. Majority of these trials are simple placebo controlled non-inferiority study designs which aims to show an absence of cardiovascular toxicity based on end point events. As per guidance, in majority of the studies major adverse CV events (MACE) has been selected as a primary end point which include CV mortality, MI and stroke and also includes hospitalization for acute coronary syndrome, urgent revascularization procedures and heart failure (HF) [7].

\section{Cardiovascular outcome trials from the past}

The pathophysiological process which drives CV disease in the diabetic population is complex and the clinical outcome is influenced by multiple pathways and needs interventions in different causal pathways simultaneously. Accelerated atherosclerosis is one such mechanism which influences increased risk of CV disease in type 2 diabetes. Surrogate endpoints like "optimal glycaemic control" monitored by HbA1c may actually fail to reflect the true clinical outcome hence most of the CV trials now focus on cardiovascular endpoints like $\mathrm{CV}$ death, fatal or non-fatal MI and stroke.

In the past large scale landmark trials like United Kingdom Prospective Diabetes Study (UKPDS) have tried to address the effects of HbA1c lowering on CV outcomes [8,9]. In this trial, the effect of intensive glucose lowering on micro vascular effects were undisputed ( $25 \%$ relative risk reduction, $p=0.0099$ ) after a follow up of 10 years compared to the conventional therapy but the relative risk reduction for $\mathrm{Ml}$ reached borderline significance only $(16 \%, p=0.052)$ and there was no significant reduction in all cause death, stroke or composite of any diabetes related end point $[\mathbf{8 , 9}$. It was only with a further 10 years of post interventional trial follow up, significant risk reductions were noted for $\mathrm{MI}(15 \%, \mathrm{p}=0.01)$ and all cause mortality $(13 \%, p=0.007)$ in the former intensive group with greater results in the metformin subgroup [10].

Further large scale studies have tried to evaluate the efficacy of intensive versus standard glucose lowering strategies on CV outcomes. The Action to Control Cardiovascular Risk in Diabetes (ACCORD) trial with a median follow up of 3.7 years showed a significant decrease rate of non-fatal MI but was stopped prematurely because of an unexpected $22 \%$ increased relative risk of all cause mortality from CV deaths in the intensive treatment group [11]. The Action in Diabetes and Vascular disease: Preterax and Dimicron MR Controlled Evaluation (ADVANCE) trial had a median follow up of 5 years and reported a statistically significant $10 \%$ reduction in the primary endpoint of major macro vascular and micro vascular events in the intensive glycemic group (HR: $0.90,95 \% \mathrm{Cl}$ : 0.82-0.98) but when analysed separately the effect on macro vascular outcomes were not significant (HR: $0.94,95 \% \mathrm{Cl}$ : 0.841.06) [12]. The Veterans Affairs Diabetes trial (VADT) included a similar standard treatment and an intensive therapy arm with a median follow up of 5.6 years. It didn't find any significant benefit in time to the first occurrence of a $\mathrm{CV}$ event in the intensive group (HR: $0.88 ; 95 \% \mathrm{Cl}, 0.74-1.05 ; \mathrm{p}=0.14$ ) and the observed event rate was $33.5 \%$ in the standard and $29.5 \%$ in the intensive group respectively with a relative reduction of $11.9 \%$. There was no significant difference between the two groups in any component of the primary outcome or in the rate from death from any cause (HR: 1.07; $95 \% \mathrm{Cl}, 0.81-1.42$; $\mathrm{p}=0.62$ ). The conclusion from this trial was very similar to other trials like ADVANCE, ACCORD which didn't show any association between intensive glycemic control and risk reduction of CV events [13]. All these trials [11-13] had large sample size and up to 5 years of follow up, but they only showed non-significant trends towards reduced risk in their primary cardiovascular endpoints with allocation of intensive glycemic therapy. These trials enrolled patients with long standing diabetes and it remains a topic of debate whether the response would have been different in a newly diagnosed diabetes population but it reliably proved the principle that glycemic control alone is not a reliable surrogate marker for reduction of $\mathrm{CV}$ events. However, a meta-analysis by Turnbull et al of these three trials together with first 5 years of follow up data from UKPDS showed a significant reduction of MACE and particularly a risk reduction in $\mathrm{MI}$ with intensive glucose lowering [14]. There were other trials which looked into CV events and mortality endpoints and did not solely concentrate on glucose lowering strategies. In the RECORD trial [15] rosiglitazone was associated with higher risk of death or HF related hospitalization (HR: $2.10,95 \% \mathrm{Cl}: 1.35-3.27$ ) but in the post marketing study, no excess risk of $\mathrm{CV}$ events were noted other than HF and meta-analyses including RECORD have not shown convincing harm beyond the previously known excess risk of HF [16]. The PROactive study compared the use of pioglitazone with placebo added to usual diabetes care. In their follow up of more than 5000 patients for an average duration of 34.5 months they found a non significant trend for a $10 \%$ relative risk reduction in the primary composite $\mathrm{CV}$ end point but showed an increased incidence of HF. Although HF was not a pre-specified endpoint in this trial but the hazard ratio for hospital admission for HF was high in the pioglitazone group (HR: 1.41, 95\% Cl, 1.1-1.8, $\mathrm{p}=0.007$ ) [17].

The earlier trials focussed on whether the changes in glycaemic control (monitored by $\mathrm{HbA} 1 \mathrm{c}$ ) would reduce $\mathrm{CV}$ risk and would produce beneficial effect but to postulate such an outcome patients needed longer follow up. These longer trials allowed better characterization of efficacy and safety profiles of the drugs that were intended for type 2 diabetes but it incurred more cost, poor patient retention and often missing data at a later stage.

\section{Recent cardiovascular outcome trials}

The US FDA and European Medicines Agency's (EMA) requirement for CV safety of hypoglycaemic agents in addition to glycaemic efficacy has lead to a paradigm shift by which recent CV outcomes trials are conducted. In order to comply with 
the regulatory requirements large scale studies have been and are being conducted which involves huge sample size, multiple countries with geographic and demographic variations and for a shorter follow up period and it is expected that majority will be reported by 2020 [18]. The major surprise that has sprung up is that majority of these trials are using a non-inferiority design which essentially shows that the new drug is not materially worse than the control. It seeks to show that any difference between the two treatments is small enough to allow a conclusion that the new drug has at least some effect or, in many cases, an effect that is not too much smaller than the active control. In contrast a superiority trial would have shown that the new drug would be more effective than a control (placebo, no treatment, or a lower dose of the test drug) [19]. The downside on a non-inferiority design is that it will aptly demonstrate the safety of the drug with minimal focus on its efficacy. Moreover the limited timeline allotted for these studies may potentially predict no harm in the high risk groups for CV disease but extended follow up periods are usually required to detect safety signals in low risk patients [20].

In the last few years there is a wave of cardiovascular intervention trials which have been conducted with the di-peptidyl peptidase 4 inhibitors (DPP-4). In the Examination of Cardiovascular Outcomes with Alogliptin versus Standard of Care (EXAMINE) trial with a median follow up of 1.8 years Alogliptin was studied as an addition to existing anti-hyperglycaemic treatment in comparison to a placebo in patients with type 2 diabetes who had an acute coronary event in the last 15-90 days prior to randomization. The study showed that a primary end point (composite death from CV disease, non-fatal MI, non-fatal stroke) was $11.3 \%$ in the Alogliptin group compared to $11.8 \%$ in the placebo group (HR: 0.96, upper boundary of one sided repeated $\mathrm{Cl}, 1.16$ : $\mathrm{p}<$ 0.001 for non-inferiority) suggesting that the rates of major $\mathrm{CV}$ events were not raised with Alogliptin in comparison to a placebo [21]. This was followed by the results from the Saxagliptin Assessment of Vascular Outcomes recorded in Patients with Diabetes Mellitus- Thrombolysis in Myocardial Infarction 53 (SAVOR-TIMI 53) trial with a median follow up of 2.1 years which evaluated saxagliptin against a placebo showing similar results for a cardiovascular primary endpoint (7.3\% and $7.2 \%$ respectively, HR: $1.00 ; 95 \% \mathrm{Cl} 0.89$ to 1.12 $p=0.99$ for superiority and $p<0.001$ for non-inferiority). This suggested that saxagliptin did not increase or decrease rate of ischemic events but an unexpected outcome showed patient in the saxagliptin group with an increased admission with heart failure compared to the placebo $(3.5 \%$ Vs $2.8 \%$, HR: $1.27 ; 95 \% \mathrm{Cl} 1.07-1.51, \mathrm{p}<0.007$ ) [22]. The possible explanation for this was shown in a later sub-analysis which concluded that subjects who had greater risk of hospitalization with $\mathrm{HF}$ were those who had an eGFR $<60 \mathrm{mls} / \mathrm{min}$, had previous history of heart failure and with elevated baseline levels of $N$ terminal pro B type natriuretic peptide (NT-proBNP) [23]. The latest published data reflecting a similar trend was in the Trial Evaluating Cardiovascular Outcomes with Sitagliptin (TECOS) where patients had a median follow up of three years and showed that sitagliptin was considered to be non-inferior to placebo for primary composite CV outcomes (HR: 0.98; $95 \%$ $\mathrm{Cl}, 0.88$ to $1.09 ; \mathrm{p}<0.001)$ and the total number of primary outcome that occurred were $11.4 \%$ (4.06 per 100 person years) in sitagliptin group in comparison to $11.6 \%$ (4.17 per 100 person years) in the placebo group. Moreover the rate of hospitalization for heart failure did not differ between the two groups (HR: $1.00 ; 95 \% \mathrm{Cl}, 0.83$ to $1.20 ; p=0.98$ ) [24]. The population that were studied in these three trials [2124] were very similar and the patients had well managed cardiovascular and glycemic risk factors at baseline. These trials also suggested that the catalytic inhibition of DPP-4 is basically safe for the $\mathrm{CV}$ standpoint but such inhibition alone is insufficient to improve CV outcomes in such short term and longer follow up is necessary. Most of the CV outcome trials with the DPP-4 inhibitors were conducted in a placebo controlled setting with no active comparator. This leads to a limitation in clinical interpretation and does not allow an assessment of comparative effectiveness.

Sulfonylurea's (SU) have been always recommended to be the preferred second line agents for type 2 diabetes after metformin and there have been uncertainty of its long term CV safety in the University group Diabetes Programme (UGDP) [25]. It is uncertain whether the UGDP findings are applicable to modern clinical management of diabetes but a recent meta-analysis of 40 randomized controlled trials (RCT's) didn't show any increased risk of macro vascular disease and all cause mortality with second generation SU's versus other oral agents or placebo [26]. As the DPP-4 inhibitors are often considered to be the second line agents, the Cardiovascular outcome study of Linagliptin versus Glimiperide in patients with type 2 diabetes (CAROLINA) will stand out which compares Linagliptin with an active SU comparator, glimiperide for $\mathrm{CV}$ safety. The results will help to address the inconsistencies regarding CV safety of SU's and will also aid in future decision making process regarding the choice of second line agents as an add on to metformin if linagliptin is found to be superior to glimiperide [27]. As CAROLINA has no placebo group to calibrate any findings to the population being studied a second study called Cardiovascular safety and Clinical Outcome with linagliptin (CARMELINA) is being carried out by the same sponsors who will compare the CV and renal safety of linagliptin versus placebo when added to standard care in type 2 diabetes. This will be the first large scale outcome study dedicated for evaluating of tangible renal outcomes with a DPP-4 inhibitor in comparison with a placebo and the results will be expected after 2018 [28].

In the other subclasses of oral hypoglycaemic agents the Sodium Glucose Transporter 2 (SGLT 2) inhibitors have generated avid interest in the last few years. The multicentre trial to evaluate the effect of Dapagliflozin on the incidence of 
cardiovascular events (DECLARE-TIMI 58) [29] and Canagliflozin cardiovascular assessment study (CANVAS) [30] are the two large scale studies which are currently ongoing and assessing the impact of SGLT 2 inhibitors on the CV risk for MACE. The $\{B I$ 10773 (EMPAGLIFLOZIN) Cardiovascular Outcome Event Trial in Type 2 Diabetes Mellitus Patients (EMPA- REG OUTCOME)\} [31] is a similar study that has been completed in 2015 and is expected to publish their results on primary CV outcome measures with the use of Empagliflozin (10 and $25 \mathrm{mg}$ ) in comparison to usual care in patients with high CV risk. It is interesting to note that all the CV safety trials with SGLT2 inhibitors will be of longer duration (time frame up to 4-6 years) when compared to that with DPP-4 inhibitors associated trials.

A major challenge for the clinicians currently is to make the right choice for the patients in determining which oral agents will be most effective for reducing blood glucose and would also minimise $\mathrm{CV}$ risk. To add the on going debate and to the wealth of data that is available with the newer agents and to close the gap on uncertainties concerning earlier agents, the Thiazolidinediones or Sulfonylurea's and Cardiovascular Accidents Intervention Trial (TOSCA.IT) has been designed by the Italian Society of Diabetology and supported by the Italian Medicine Agency and Diabete Ricerca, a non profit foundation of the Italian Diabetes society [32]. This is a randomized, parallel group, non-blinded trial which is purely an institutional trial and not supported by any industry. This trial has been drafted as a head to head comparison between pioglitazone and SU's. It will provide evidence based information between two old, widely used and less expensive drugs used for management of diabetes when metformin alone is not effective. Moreover, it will also throw light on the primary efficacy outcome (all cause mortality, non fatal MI, non fatal stroke and unplanned coronary re-vascularisation) and several secondary outcomes over a follow up period of $\mathbf{4 8}$ months. In contrast to other recent trials TOSCA.IT is unique as it is a head to head study exploring the effect of anti-diabetes drugs on CV events as opposed to the non-inferiority design of other recent trials.

\section{The current challenges of cardiovascular outcome trials} As cardiovascular disease remains the leading cause of mortality and morbidity in type 2 diabetes it is imperative that the benefit and risk of oral agents are defined appropriately. The current generation of CV outcome trials needs a significant revamp as majority of them are short lived, measuring limited outcomes at a very high cost. The non-inferiority design has ballooned following guidance from the regulatory authorities like US FDA, EMA and similar regulatory bodies across the world. The designs of recent trials also limits direct head to head comparative analysis and puts significant constraints in studying long term clinical outcomes which is related to a chronic disease like type 2 diabetes.

It is understandable that long term trials will incur more cost and will have problems with retention and adherence but if the geographical areas, study population and previous study metrics relevant to particular centres are studied properly then the limitation of "drop outs" can be minimised. In the current climate, the studies are larger and more comprehensive and include $\mathrm{CV}$ high risk patients but the need to conduct such post appro val CV outcome studies the sponsors are shelling out an enormous amount of money. Currently, the huge market for drugs relating to type 2 diabetes is enabling the pharmaceutical companies to bear the cost of such trials but every company may not have the same expertise and resources which will serve as a major hindrance to smaller units for developing anti-diabetes medicines in the future. Moreover it will also lead to premature termination of studies done by non sponsored individual institutions which will lead to a complete failure of independent research and a formal abdication to the industry. Several countries do not need CV outcome data for the approval of anti-diabetic medications which would suggest that future trials needs comprehensive designs which takes in to account the choice of patient population, demographic and cultural differences, local practices, heterogeneity of treatment effect and also focus on cost. These studies should also have extended follow up for better characterization of efficacy and safety profiles of drugs intended to treat chronic diseases like diabetes.

\section{Conclusion}

CV disease will always remain an integral aspect of diabetes management. Although previous long term studies have shown the benefit of risk reduction in micro vascular complications with intensive glucose lowering but none have shown similar beneficial cardiovascular effects. The current safety trials and the non inferiority designs used to determine the CV outcomes relating to anti-diabetes medications are providing a pseudo blanket to our understanding of the CV effects of the newer agents and pose significant cost and conduct challenges. Future trials should be designed keeping in mind that the primary reason of developing newer agents is to have more effect on glucose lowering and the drugs should be judged based on its ability to influence multidimensional clinical outcomes. Secondly, the studies should be robust and stratified which takes into account geographical differences and variations in background and ancillary therapy and their adverse effect profile. Thirdly, the study designs should be more adaptive and include head to head comparisons between newer novel agent and established existing treatments with extended follow up periods for better characterization and to evaluate the time dependent risk-benefit profile. Finally, the regulatory bodies should a have rethink on their strategy for drug approval relating to type 2 diabetes as the current trials are enormously costly and consuming huge amount of resources which may pose a major risk to future anti diabetes drug development.

\section{Competing interests}

The author declares that he has no competing interests. 


\section{Publication history}

Editors: Elias S. Siraj, Temple University School of medicine, USA. Ippei Kanazawa, Shimane University Faculty of Medicine, Japan. EIC: Geoffrey Burnstock, University College London, UK.

Received: 22-Jul-2015 Final Revised: 24-Aug-2015

Accepted: 01-Sep-2015 Published: 04-Sep-2015

\section{References}

1. Seshasai SR, Kaptoge S, Thompson A, Di Angelantonio E, Gao P, Sarwar N, Whincup PH, Mukamal KJ, Gillum RF, Holme I and Njolstad I et al. Diabetes mellitus, fasting glucose, and risk of cause-specific death. $N$ Engl J Med. 2011; 364:829-41. | Article | PubMed Abstract | PubMed Full Text

2. Stratton IM, Adler AI, Neil HA, Matthews DR, Manley SE, Cull CA, Hadden D, Turner RC and Holman RR. Association of glycaemia with macrovascular and microvascular complications of type 2 diabetes (UKPDS 35): prospective observational study. BMJ. 2000; 321:405-12. Article | PubMed Abstract | PubMed Full Text

3. Thompson CS. Animal models of diabetes mellitus: relevance to vascular complications. Curr Pharm Des. 2008; 14:309-24. | Article | PubMed

4. Selvin E, Marinopoulos S, Berkenblit G, Rami T, Brancati FL, Powe NR and Golden SH. Meta-analysis: glycosylated hemoglobin and cardiovascular disease in diabetes mellitus. Ann Intern Med. 2004; 141:421-31. | Article I PubMed

5. Nissen SE and Wolski K. Effect of rosiglitazone on the risk of myocardial infarction and death from cardiovascular causes. N Engl J Med. 2007; 356:2457-71. | Article | PubMed

6. Spring S. US Food and Drug Administration. Guidance for industryDiabetes Mellitus-Evaluating cardiovascular risk in new antidiabetic therapies to treat type 2 diabetes. 2008. | Website

7. Hirshberg B and Katz A. Cardiovascular outcome studies with novel antidiabetes agents: scientific and operational considerations. Diabetes Care. 2013; 36 Suppl 2:S253-8. | Article | PubMed Abstract | PubMed Full Text

8. Effect of intensive blood-glucose control with metformin on complications in overweight patients with type 2 diabetes (UKPDS 34). UK Prospective Diabetes Study (UKPDS) Group. Lancet. 1998; 352:85465. | Article | PubMed

9. Intensive blood-glucose control with sulphonylureas or insulin compared with conventional treatment and risk of complications in patients with type 2 diabetes (UKPDS 33). UK Prospective Diabetes Study (UKPDS) Group. Lancet. 1998; 352:837-53. I Article I PubMed

10. Holman RR, Paul SK, Bethel MA, Matthews DR and Neil HA. 10-year follow-up of intensive glucose control in type 2 diabetes. $N$ Engl J Med. 2008; 359:1577-89. | Article | PubMed

11. Gerstein HC, Miller ME, Byington RP, Goff DC, Jr., Bigger JT, Buse JB, Cushman WC, Genuth S, Ismail-Beigi F, Grimm RH, Jr., Probstfield JL, Simons-Morton DG and Friedewald WT. Effects of intensive glucose lowering in type 2 diabetes. N Engl J Med. 2008; 358:2545-59. | Article | PubMed Abstract | PubMed Full Text

12. Patel A, MacMahon S, Chalmers J, Neal B, Billot L, Woodward M, Marre M, Cooper M, Glasziou P and Grobbee D et al. Intensive blood glucose control and vascular outcomes in patients with type 2 diabetes. $N$ Engl J Med. 2008; 358:2560-72. | Article | PubMed

13. Duckworth W, Abraira C, Moritz T, Reda D, Emanuele N, Reaven PD, Zieve FJ, Marks J, Davis SN, Hayward R, Warren SR, Goldman S, McCarren M, Vitek ME, Henderson WG and Huang GD. Glucose control and vascular complications in veterans with type 2 diabetes. N Engl J Med. 2009; 360:129-39. | Article | PubMed

14. Turnbull FM, Abraira C, Anderson RJ, Byington RP, Chalmers JP, Duckworth WC, Evans GW, Gerstein HC, Holman RR, Moritz TE, Neal BC, Ninomiya T, Patel AA, Paul SK, Travert F and Woodward M. Intensive glucose control and macrovascular outcomes in type 2 diabetes.
Diabetologia. 2009; 52:2288-98. | Article | PubMed

15. Home PD, Pocock SJ, Beck-Nielsen H, Curtis PS, Gomis R, Hanefeld M, Jones NP, Komajda M and McMurray JJ. Rosiglitazone evaluated for cardiovascular outcomes in oral agent combination therapy for type $\mathbf{2}$ diabetes (RECORD): a multicentre, randomised, open-label trial. Lancet. 2009; 373:2125-35. | Article | PubMed

16. US Department of Health and Human Services, food and drug administration. Briefing document. Readjudication of the rosiglitazone evaluated for cardiovascular outcomes and regulation of glycaemia in diabetes trial (RECORD). Joint meeting of the Endocrinologic and metabolic drugs advisory committee. 2013. I Pdf

17. Dormandy JA, Charbonnel B, Eckland DJ, Erdmann E, Massi-Benedetti M, Moules IK, Skene AM, Tan MH, Lefebvre PJ and Murray GD et al. Secondary prevention of macrovascular events in patients with type 2 diabetes in the PROactive Study (PROspective pioglitAzone Clinical Trial In macroVascular Events): a randomised controlled trial. Lancet. 2005; 366:1279-89. | Article | PubMed

18. Holman RR, Sourij $H$ and Califf RM. Cardiovascular outcome trials of glucose-lowering drugs or strategies in type 2 diabetes. Lancet. 2014; 383:2008-17. | Article | PubMed

19. Pocock SJ. The pros and cons of non inferiority trials. Fundamental \& Clinical Pharmacology. 2003; 17:483-90. I Pdf

20. Zannad F, Stough WG, Pocock SJ, Sleight P, Cushman WC, Cleland JG, McMurray JJ, Lonn E, Geller NL, Wedel H, Abadie E, Alonso-Garcia A and Pitt B. Diabetes clinical trials: helped or hindered by the current shift in regulatory requirements? Eur Heart J. 2012; 33:1049-57. | Article | PubMed

21. White WB, Cannon CP, Heller SR, Nissen SE, Bergenstal RM, Bakris GL, Perez AT, Fleck PR, Mehta CR, Kupfer S, Wilson C, Cushman WC and Zannad F. Alogliptin after acute coronary syndrome in patients with type 2 diabetes. N Engl J Med. 2013; 369:1327-35. | Article | PubMed

22. Scirica BM, Bhatt DL, Braunwald E, Steg PG, Davidson J, Hirshberg B, Ohman P, Frederich R, Wiviott SD, Hoffman EB, Cavender MA, Udell JA, Desai NR, Mozenson O, McGuire DK, Ray KK, Leiter LA and Raz I. Saxagliptin and cardiovascular outcome in patients with type 2 diabetes mellitus. N Engl J Med. 2013; 369:1317-26. | Article

23. Scirica BM, Braunwald E, Raz I, Cavender MA, Morrow DA, Jarolim P, Udell JA, Mosenzon O, Im K, Umez-Eronini AA, Pollack PS, Hirshberg B, Frederich R, Lewis BS, McGuire DK, Davidson J, Steg PG and Bhatt DL. Heart failure, saxagliptin, and diabetes mellitus: observations from the SAVOR-TIMI 53 randomized trial. Circulation. 2014; 130:1579-88. | Article I PubMed

24. Green JB, Bethel MA, Armstrong PW, Buse JB, Engel SS, Garg J, Josse R, Kaufman KD, Koglin J, Korn S, Lachin JM, McGuire DK, Pencina MJ, Standl E, Stein PP, Suryawanshi S, Van de Werf F, Peterson ED and Holman RR. Effect of Sitagliptin on Cardiovascular Outcomes in Type 2 Diabetes. $N$ Engl J Med. 2015; 373:232-42. | Article I PubMed

25. Meinert CL, Knatterud GL, Prout TE and Klimt CR. A study of the effects of hypoglycemic agents on vascular complications in patients with adult-onset diabetes. II. Mortality results. Diabetes. 1970; 19:Suppl:789-830. | PubMed

26. Selvin E, Bolen S, Yeh HC, Wiley C, Wilson LM, Marinopoulos SS, Feldman L, Vassy J, Wilson R, Bass EB and Brancati FL. Cardiovascular outcomes in trials of oral diabetes medications: a systematic review. Arch Intern Med. 2008; 168:2070-80. | Article | PubMed Abstract | PubMed Full Text

27. Rosenstock J, Marx N, Kahn SE, Zinman B, Kastelein JJ, Lachin JM, Bluhmki E, Patel S, Johansen OE and Woerle HJ. Cardiovascular outcome trials in type 2 diabetes and the sulphonylurea controversy: rationale for the active-comparator CAROLINA trial. Diab Vasc Dis Res. 2013; 10:289-301. | Article | PubMed

28. Cardiovascular and Renal Microvascular Outcome Study With Linagliptin in Patients With Type 2 Diabetes Mellitus (CARMELINA). 2013-2018. | Website

29. Multicenter Trial to Evaluate the Effect of Dapagliflozin on the Incidence of Cardiovascular Events (DECLARE-TIMI58). 2012-2019. | Website 
Gautam Das, Journal of Diabetes Research \& Clinical Metabolism 2015,

30. CANVAS-CANagliflozin cardioVascular Assessment Study. 2009-2017. | Website

31. Zinman B, Inzucchi SE, Lachin JM, Wanner C, Ferrari R, Fitchett D, Bluhmki E, Hantel S, Kempthorne-Rawson J, Newman J, Johansen OE, Woerle $\mathrm{HJ}$ and Broedl UC. Rationale, design, and baseline characteristics of a randomized, placebo-controlled cardiovascular outcome trial of empagliflozin (EMPA-REG OUTCOME). Cardiovasc Diabetol. 2014; 13:102. | Article | PubMed Abstract | PubMed Full Text

32. Vaccaro O, Masulli M, Bonora E, Del Prato S, Nicolucci A, Rivellese AA and Riccardi G. The TOSCA.IT trial: a study designed to evaluate the effect of pioglitazone versus sulfonylureas on cardiovascular disease in type 2 diabetes. Diabetes Care. 2012; 35:e82. | Article | PubMed Abstract | PubMed Full Text

\section{Citation:}

Das G. Cardiovascular outcome trials in type 2 diabetes: what have we learned from the past and present? J Diab Res Clin Met. 2015; 4:3.

http://dx.doi.org/10.7243/2050-0866-4-3 